\title{
An Under-Appreciated Source of Reproducibility Issues in Cross- Coupling: Solid-State Decomposition of Primary Sodium Alkoxides in Air
}

\author{
Robert Wethman ${ }^{\dagger}$, Joseph Derosa ${ }^{\star}$, Van T. Tran ${ }^{\star}$, Taeho Kang $\$$, Omar Apolinar ${ }^{\star}$, Anuji Abraham ${ }^{\S}$, Roman \\ Kleinmans ${ }^{\ddagger}$, Steven R. Wisniewski ${ }^{{ }^{*}}$, John R. Coombs ${ }^{\dagger^{*}}$, Keary M. Engle ${ }^{\ddagger^{*}}$ \\ ${ }^{+}$Chemical Process Development, Bristol Myers Squibb, One Squibb Drive, New Brunswick, New Jersey 08903, United States \\ ${ }^{\ddagger}$ Department of Chemistry, Scripps Research, 10550 North Torrey Pines Road, La Jolla, California 92037, United States \\ ${ }^{\S}$ Material Science and Engineering, Bristol Myers Squibb, One Squibb Drive, New Brunswick, New Jersey 08903, United States \\ KEYWORDS: Cross-coupling, sodium alkoxide, palladium, nickel, solid-state chemistry.
}

\begin{abstract}
The decomposition of primary sodium alkoxide salts under ambient storage conditions and the effects of this phenomenon on commonly employed transition-metal-catalyzed cross-coupling reactions are described. By utilizing NMR, IR, and Raman spectroscopy, along with a modified Karl Fischer analysis, the main inorganic degradants were characterized, and $\mathrm{CO}_{2}$ in the air was found to be a critical reactant within the decomposition process. The effects of storage conditions on decomposition were evaluated, and the preliminary experiments to understand the kinetics of this process were performed.
\end{abstract}

Metal alkoxide salts are widely used bases in organic synthesis. ${ }^{[1]}$ Sodium salts derived from primary alcohols (i.e., $\mathrm{NaOMe}$ and $\mathrm{Na}$ $\mathrm{OEt}$ ) are among the simplest, most ubiquitous, and most commonly employed. ${ }^{[2]}$ In particular, they find widespread use in SuzukiMiyaura cross-couplings and related methods that constitute core synthetic technology in academia and industry (Figure 1A). ${ }^{[3]}$ These alkoxide bases can be synthesized using classical procedures from the literature or purchased from essentially all major commercial vendors, either as solutions or in the solid state.

During the course of research on metal-catalyzed cross-coupling reactions in our research laboratories (Figure 1B), we experienced batch-to-batch reproducibility issues in reactions employing commercial lots of $\mathrm{NaOMe}$ or $\mathrm{NaOEt} .{ }^{[4]}$ After a systematic investigation, the issues of reproducibility were determined to originate from the alkoxide base, which prompted a detailed investigation to understand (1) the differences between these lots of free-flowing white or off-white powders, which appear similar across lots by visual inspection (Figure 1C and D) and (2) the consequences of these composition differences on cross-coupling reactivity. Though the air instability of these salts has been discussed in several literature accounts, it is commonly believed that the predominant degradant is $\mathrm{NaOH}$ from trace moisture in the air. ${ }^{[5]}$ Herein, we show that decomposition of solid $\mathrm{NaOMe}$ and $\mathrm{NaOEt}$ in air is more pervasive and more complex than has been previously appreciated. As a consequence, it is likely that synthetic chemists unknowingly use degraded batches of these bases on a regular basis. We anticipate that the findings described below will directly impact alkoxide base screening in organic and organometallic reaction development and will allow rationalization of idiosyncratic sample-to-sample reactivity differences.

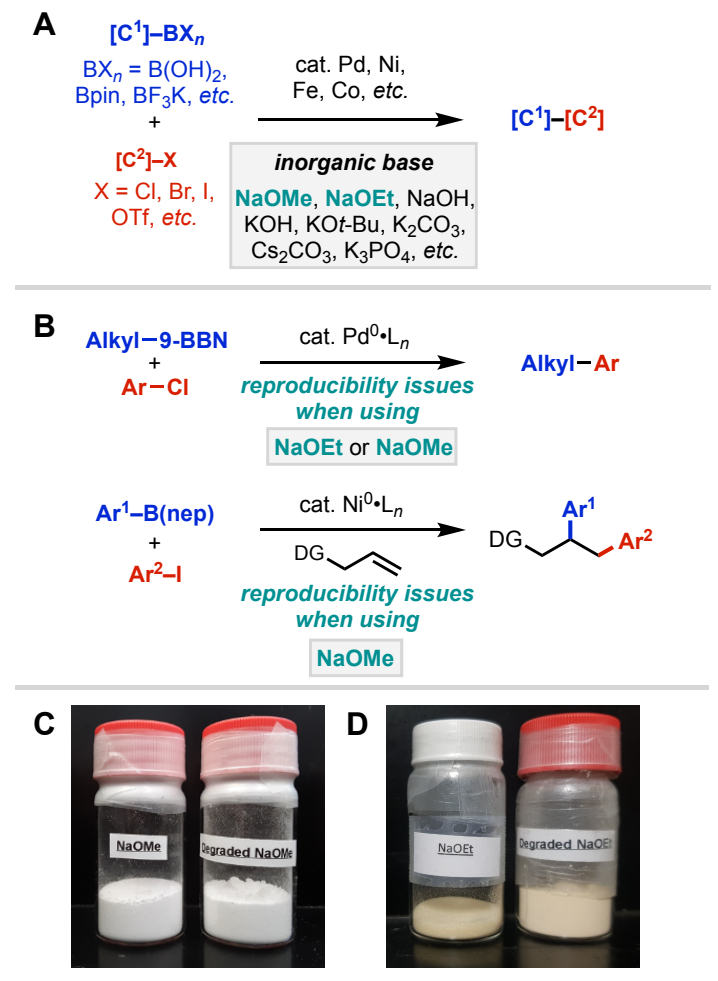

Figure 1. A) General depiction of Suzuki-Miyaura-type cross-coupling reactions that generally require inorganic base. B) Reactions of interest to our laboratories where reproducibility issues stemming from $\mathrm{Na}$ $\mathrm{OMe} / \mathrm{NaOEt}$ were first identified. C) Comparison of $\mathrm{NaOMe}$ (left) and degraded $\mathrm{NaOMe}$ (right). D) Comparison of NaOEt (left) and degraded $\mathrm{NaOEt}$ (right). 
The investigation of $\mathrm{NaOMe}$ began with a ${ }^{13} \mathrm{C}$ NMR study. ${ }^{[6]}$ When using $\mathrm{D}_{2} \mathrm{O}$ as the solvent, we attribute the peak from $\mathrm{MeOD} / \mathrm{MeOH}$ to $\mathrm{NaOMe}$. We were surprised to see that major species in one of the lots did not correspond to $\mathrm{NaOMe} / \mathrm{MeOH}$. By a comparison with reference standards, we were able to identify sodium formate and sodium carbonate as two inorganic impurities, where sodium formate is the major species (Figure 2). This commercially-obtained lot was actually a 4.5:1 ratio of sodium formate to methoxide/methanol by ${ }^{1} \mathrm{H} \mathrm{NMR}$ in $\mathrm{D}_{2} \mathrm{O} \cdot{ }^{[7]}$ Comparison of different lots of sodium methoxide showed varied levels of sodium formate and sodium carbonate. For example, under a controlled dry aerobic environment for extended times, $\mathrm{NaOMe}$ was predominantly converted to sodium formate, suggesting the degradation of sodium methoxide is highly dependent on the storage conditions. Analogous results were observed with $\mathrm{NaOEt}$ (see SI).
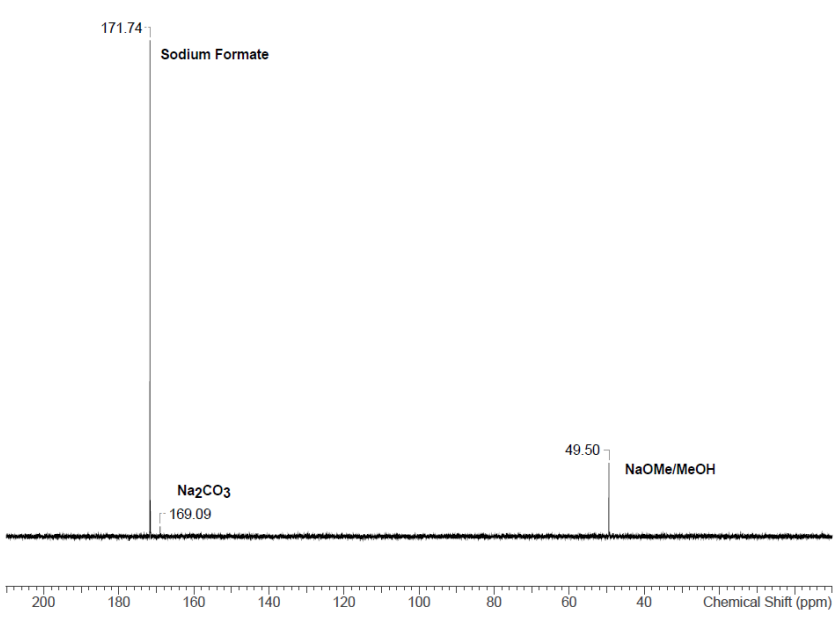

Figure $2 .{ }^{13} \mathrm{C}$ NMR of a commercially obtained lot of $\mathrm{NaOMe}$ used in initial Suzuki reaction indicating significant decomposition to $\mathrm{HCO}_{2} \mathrm{Na}$ and $\mathrm{Na}_{2} \mathrm{CO}_{3}$.

Having established a means of assaying the level of degradation of $\mathrm{NaOMe}$ and $\mathrm{NaOEt}$ lots by NMR, ${ }^{[8]}$ we then carried out a systematic study of how degradation state of the base impacts three model reactions: (a) a $\mathrm{Pd}(0)$-catalyzed $\mathrm{C}\left(\mathrm{sp}^{2}\right)-\mathrm{C}\left(\mathrm{sp}^{3}\right)$ Suzuki-Miyaura cross-coupling related to an active pharmaceutical ingredient currently under investigation at Bristol Myers Squibb, (b) a Ni(0)-catalyzed amide-directed alkene 1,2-diarylation developed in the Engle $\mathrm{lab},{ }^{[9]}$ and $(\mathrm{c})$ a $\mathrm{Ni}(0)$-catalyzed $\mathrm{C}\left(\mathrm{sp}^{2}\right)-\mathrm{C}\left(\mathrm{sp}^{3}\right)$ cross-coupling recently reported in the literature by the Watson lab. ${ }^{[10]}$

We first examined a $\mathrm{C}\left(\mathrm{sp}^{2}\right)-\mathrm{C}\left(\mathrm{sp}^{3}\right)$ Suzuki-Miyaura cross-coupling between an alkyl-9-BBN nucleophile ${ }^{[3 \mathrm{~b}]}$ and an electron-poor aryl chloride (Scheme 1). The degraded lot of NaOEt gave low yield when 1.5 or 3.0 equiv was used (Entries 1 and 2). An authentic commercial lot furnished the product in nearly quantitative yield when 1.5 equiv was used (Entry 3 ), but interestingly gave very low yield when 3.0 equiv was used (Entry 4). Comparison of Entries 2 and 4 shows that for a given base loading, degraded $\mathrm{NaOEt}$ can actually lead to higher yields than authentic material—a situation that may not be uncommon during reaction optimization. An authentic homemade lot performed similarly to the authentic commercial lot (Entry 5). Lastly, because $\mathrm{NaOEt}$ was not reproducible, we were able to obtain reliably high yield with $\mathrm{K}_{3} \mathrm{PO}_{4}$ (Entry 6).
Scheme 1. C(sp $\left.{ }^{2}\right)-C\left(s p^{3}\right)$ Suzuki-Miyaura cross-coupling

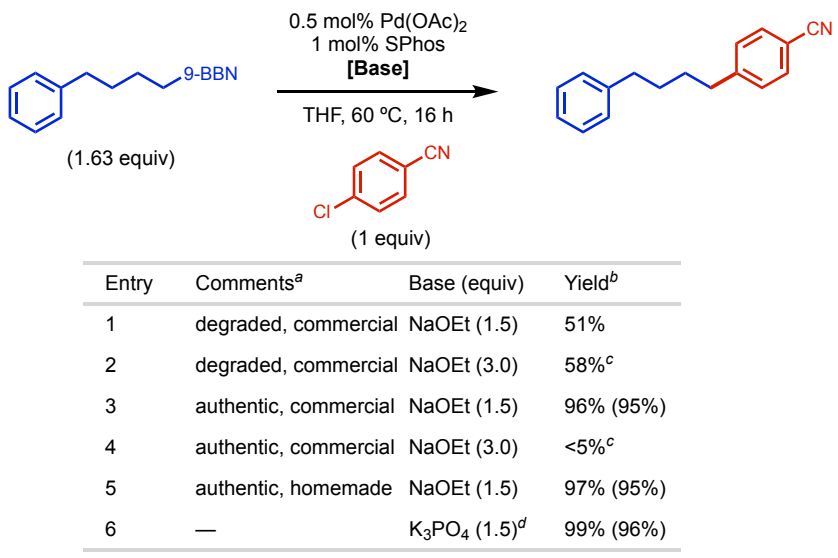

'The 'degraded' sample contained $<1 \% \mathrm{NaOEt}$ by ${ }^{1} \mathrm{H}$ NMR analysis; the 'authentic' sample contained $99 \% \mathrm{NaOEt}$ by ${ }^{1} \mathrm{H}$ NMR analysis (see SI). ${ }^{b 1} \mathrm{H}$ NMR yield with $\mathrm{CH}_{2} \mathrm{Br}_{2}$ as internal standard. Isolated yield in parentheses. Yields represent the average of two independent runs. 'Yield reflects the results of a single run. ${ }^{d} \mathrm{H}_{2} \mathrm{O}$ (5 equiv) as additive.

We then moved on to test an amide-directed nickel-catalyzed alkene 1,2-diarylation method employing an aryl iodide and an arylboronic ester coupling partner (Scheme 2), which in pilot studies showed promising reactivity with $\mathrm{NaOMe}$ as base. ${ }^{[9]}$ A degraded commercial sample was tested at two time points, roughly 20 months apart while the sample was capped under air. Over time, further degradation was evident by ${ }^{1} \mathrm{H}$ NMR. Using these two different degradation states of the $\mathrm{NaOMe}$ sample, $76 \%$ and $43 \%$ isolated yields were obtained (Entries 1 and 2), illustrating how the inherent air instability of $\mathrm{NaOMe}$ can lead to reproducibility issues over time. Authentic commercial $\mathrm{NaOMe}$ gave modest yield (Entry 3 ), while homemade $\mathrm{NaOMe}$ was slightly lower yielding (Entry 4), potentially due to seemingly minor purity differences. We were unable to develop a reproducible, robust transformation with $\mathrm{NaOMe}$, and ultimately found that reproducibly high yield could be obtained with solid $\mathrm{NaOH}$ as the base, as reported in the published protocol (Entry 5).

\section{Scheme 2. Nickel-catalyzed alkene 1,2-diarylation}

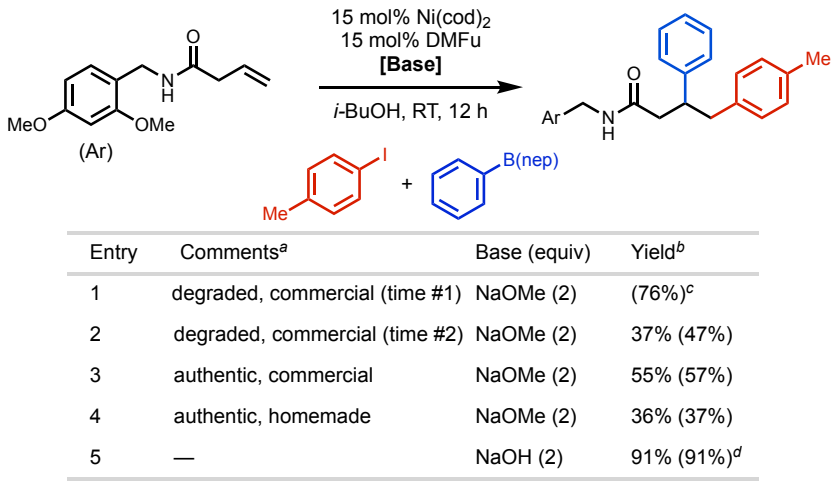

a The 'degraded' samples at time \# 1 and time \#2 refer to the same lot after 20 months of storage under air conditions with lid closed, which contained $<35 \% \mathrm{NaOMe}$ and $<21 \% \mathrm{NaOMe}$, respectively, by ${ }^{1} \mathrm{H} \mathrm{NMR}$ 
analysis; the 'authentic' sample contained $99 \% \mathrm{NaOMe}$ by ${ }^{1} \mathrm{H} \mathrm{NMR}$ analysis. ${ }^{b 1} \mathrm{H}$ NMR yield with $\mathrm{CH}_{2} \mathrm{Br}_{2}$ as internal standard. Isolated yield in parentheses. Yields represent the average of two independent runs. 'Yield reflects the result of a single run. ${ }^{d}$ In Ref. 9, 83\% yield was reported under these conditions (for a single run).

Finally, we tested a recently reported nickel-catalyzed benzylic pivalate / triaryl boroxine cross-coupling developed by the Watson lab using $\mathrm{NaOMe}$ as the base (Scheme 3$){ }^{[10]}$ The effects of base purity on reactivity were striking, with degraded material giving only $8 \%$ product yield (Entry 1), while authentic homemade and commercial samples recapitulated the high yield reported in the original report (Entries 2-4).

\section{Scheme 3. Nickel-catalyzed benzylic pivalate/boroxine cross-} coupling

\begin{tabular}{|c|c|c|c|c|}
\hline \multicolumn{4}{|c|}{$\begin{array}{c}5 \mathrm{~mol} \% \mathrm{Ni}(\mathrm{cod})_{2} \\
(\mathrm{PhBO})_{3} \\
\text { [Base] }\end{array}$} & \\
\hline Entry & \multicolumn{2}{|c|}{ Comments $^{a}$} & Base (equiv) & Yield $^{b}$ \\
\hline 1 & \multicolumn{2}{|c|}{ degraded, commercial } & $\mathrm{NaOMe}(2)$ & $8 \%$ \\
\hline 2 & \multicolumn{2}{|c|}{ authentic, commercial } & $\mathrm{NaOMe}(2)$ & $92 \%(77 \%)$ \\
\hline 3 & \multicolumn{2}{|c|}{ authentic, homemade } & $\mathrm{NaOMe}(2)$ & $92 \%$ \\
\hline 4 & \multicolumn{2}{|c|}{ as reported in Ref. 10} & $\mathrm{NaOMe}(2)$ & $(89 \%)^{c}$ \\
\hline
\end{tabular}

${ }^{a}$ The 'degraded' sample contained $<6 \% \mathrm{NaOMe}$ by ${ }^{1} \mathrm{H}$ NMR analysis; the 'authentic' sample contained $99 \% \mathrm{NaOMe}$ by ${ }^{1} \mathrm{H}$ NMR analysis. ${ }^{b 1} \mathrm{H}$ NMR Yield with $\mathrm{CH}_{2} \mathrm{Br}_{2}$ as internal standard. Isolated yield in parentheses. Yields represent the average of two independent runs. 'In Ref. 10 , an enantioenriched electrophile was employed, and the reaction proceeded in a stereoinvertive fashion. In our experiments, a racemic electrophile was used.

With reactivity data corroborating the previously established NMR data, we investigated the degraded and pure lots of $\mathrm{NaOMe}$ by Raman spectroscopy in order to establish the identity of the full suite of degradants (Figure 3) and to set the stage for in situ monitoring of this process over time (vide infra). ${ }^{[11]}$ This analysis provided additional evidence that high-quality and low-quality lots of $\mathrm{NaOMe}$ were vastly different in terms of composition. Comparison of the low-quality lot with reference standards also provides evidence for the presence of sodium formate and sodium carbonate.

The NMR and Raman techniques helped identify two inorganic impurities in $\mathrm{NaOMe}$, but neither of these two techniques can identify $\mathrm{NaOH}$, which was presumed to be present from the reaction of $\mathrm{NaOMe}$ with moisture in the air. A modified Karl Fischer analysis of the low-quality lot of $\mathrm{NaOMe}$ provided the combined percentage of sodium carbonate and sodium hydroxide impurities, but the method is not specific for either species (as sodium carbonate will react to form sodium hydroxide during the test). Although analysis of the low-quality material by this modified technique indicated significant degradation to either sodium carbonate, sodium hydroxide or a mixture of both, we were unable to specify the exact composition or presence of either material based on this test.
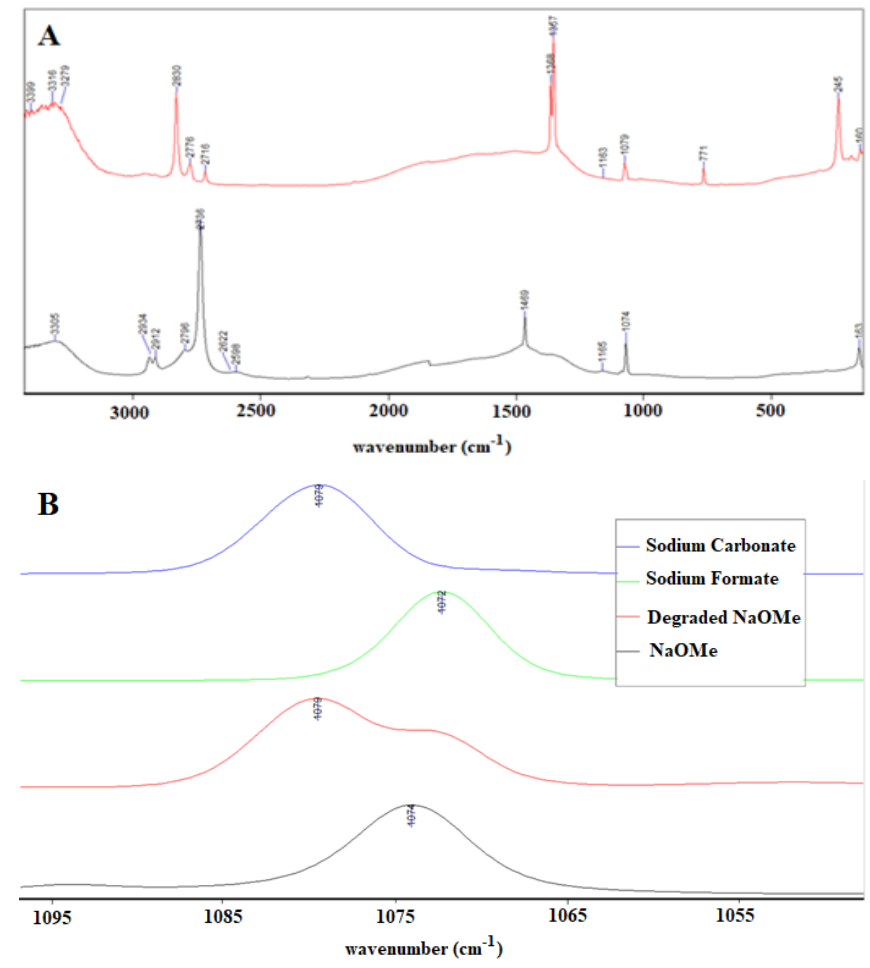

Figure 3. Raman of $\mathrm{NaOMe}$ and reference standards. A) Comparison of $\mathrm{NaOMe}$ (black) with commercially available, degraded $\mathrm{NaOMe}$ (red). B) Comparison of $\mathrm{NaOMe}$ (black) with commercially available, degraded $\mathrm{NaOMe}$ (red) along with standards of $\mathrm{Na}_{2} \mathrm{CO}_{3}$ (blue) and HCOONa (green), showing that commercially available, degraded $\mathrm{Na}$ OMe contains both $\mathrm{Na}_{2} \mathrm{CO}_{3}$ and $\mathrm{HCO}_{2} \mathrm{Na}$.

Having utilized the common spectroscopic techniques to investigate impurities, we still did not have a clear understanding of the composition of the degraded $\mathrm{NaOMe}$. To provide further clarification, we performed a series of ${ }^{23} \mathrm{Na}$ solid-state NMR (ssNMR) studies. ${ }^{[12]}$ According to the literature, $\mathrm{NaOH},{ }^{[13]} \mathrm{NaOMe},{ }^{[2 c, 14]}$ and $\mathrm{HCO}_{2} \mathrm{Na}^{[15]}$ exist as a single phase/polymorph with $\mathrm{Z}^{\prime}=1$ (one molecule in the asymmetric unit of the crystal structure). Each molecule in the asymmetric unit of the crystal structure will have a ${ }^{23} \mathrm{Na}$ atom that is represented by a quadrupolar powder pattern in ssNMR due to the quadrupolar nature of the ${ }^{23} \mathrm{Na}$ nucleus ( $\operatorname{spin}>1 / 2$ ). In the case of $\mathrm{Na}_{2} \mathrm{CO}_{3},{ }^{[16]}$ there exists the possibility for multiple polymorphs or Z' $>1$ for one polymorph. To help explain how to interpret the data, representative simulated spectra using DMFit ${ }^{[17]}$ for two inequivalent sodium species are shown in Figure 4. The entire signal represents the $\mathrm{Na}$ environment, and it is clear looking at the spectra that these two ${ }^{23} \mathrm{Na}$ resonances represent two different species. 

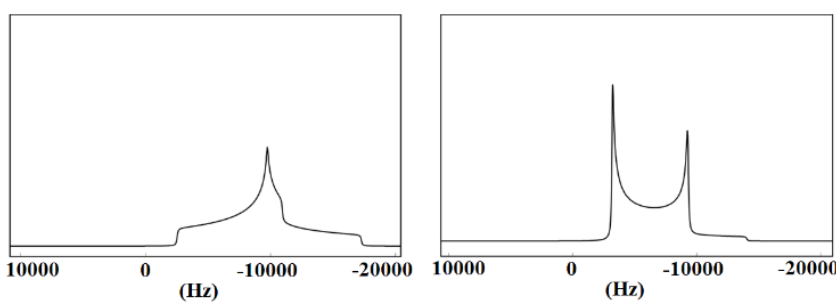

Figure 4. Representative spectral simulation (using DMFit) for ${ }^{23} \mathrm{Na}$ (Spin $=3 / 2$ ) with a quadrupolar coupling constant $\left(\mathrm{C}_{\mathrm{Q}}\right)$ of $4.5 \mathrm{MHz}$ and quadrupolar asymmetry parameters, $\eta$ of 1 (left) and 0 (right) under static conditions. These patterns represent the central transitions of spin $3 / 2\left({ }^{23} \mathrm{Na}\right)$, broadened by quadrupolar interaction to the second order, under magic angle spinning (MAS).

The stacked quadrupolar powder patterns clearly show different ${ }^{23} \mathrm{Na}$ environments for the degraded $\mathrm{NaOMe}$ and reference standards, which allows us to visually compare the spectra (Figure 5). Note that for the degraded $\mathrm{NaOMe}$ to be $100 \%$ pure, it would have to be an identical match to the $\mathrm{NaOMe}$ standard. Any difference between the spectra corresponds to an impurity present in the degraded lot. Two different degraded lots were analyzed for comparison. As they are inequivalent to each other, there are varying degrees of decomposition in the two different lots. Comparison of the degraded lots to the $\mathrm{NaOMe}$ standard show very different spectra, providing further evidence for the decomposition of $\mathrm{NaOMe}$. The degraded spectra show some common features compared to the three inorganic impurity reference standards $\left(\mathrm{Na}_{2} \mathrm{CO}_{3}, \mathrm{HCO}_{2} \mathrm{Na}\right.$, and $\mathrm{NaOH}$ ), but it is not an exact match for any of them either, suggesting that the degraded $\mathrm{NaOMe}$ is a mixture of the three inorganic salts.

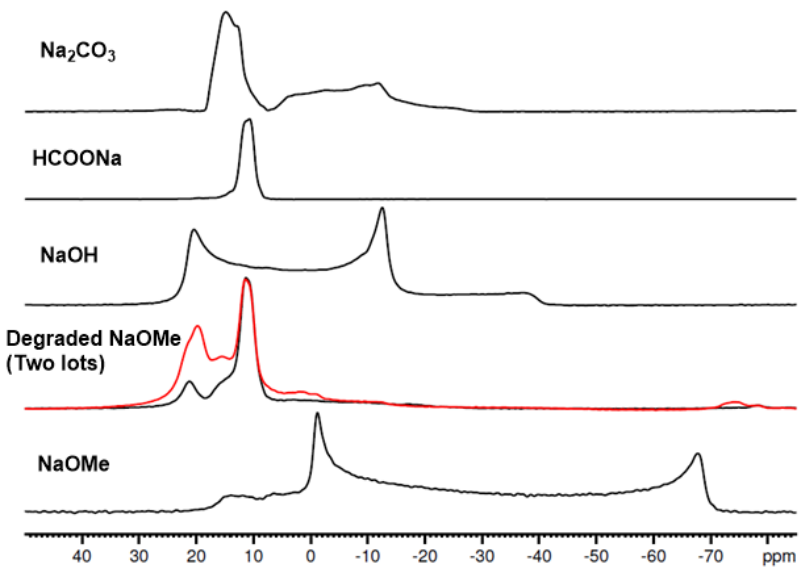

Figure 5. ${ }^{23} \mathrm{Na} \mathrm{NMR}$ of $\mathrm{NaOMe}$ samples and reference standards. Authenic $\mathrm{NaOMe}$ (bottom) and two degraded $\mathrm{NaOMe}$ samples (second from bottom).

One of the benefits of utilizing ${ }^{23} \mathrm{Na}$ ssNMR is the ability to fit the spectral data in order to calculate the composition of the degraded $\mathrm{NaOMe}$ based to the standard spectra. Based on the NMR spectral fitting by DMFit, one lot of degraded $\mathrm{NaOMe}$ (black spectrum, Figure 5) can be fitted into four components ${ }^{[18]}$ that are comprised of only two degradants $\left(\mathrm{Na}_{2} \mathrm{CO}_{3}\right.$ and $\left.\mathrm{HCO}_{2} \mathrm{Na}\right)$ (Table 1). While the first component can be assigned to $\mathrm{Na}_{2} \mathrm{CO}_{3}$ or $\mathrm{HCO}_{2} \mathrm{Na}$, the next three match either $\mathrm{Na}_{2} \mathrm{CO}_{3}$ or $\mathrm{HCO}_{2} \mathrm{Na}$, providing further evidence for the presence of these two inorganic salts as the two main degradation products. This analysis also suggests that contrary to the common belief that $\mathrm{NaOH}$ is formed when $\mathrm{NaOMe}$ is exposed to moisture in the air, $\mathrm{NaOH}$ is not present in the two degraded lots of $\mathrm{Na}$ OMe tested by ${ }^{23} \mathrm{Na}$ ssNMR. Further, if we assume that modified Karl Fischer analysis was only testing for $\mathrm{Na}_{2} \mathrm{CO}_{3}$, the Karl Fischer analysis showed $40 \% \mathrm{Na}_{2} \mathrm{CO}_{3}$, which corresponds to the spectral fit data. Therefore, the degradation of $\mathrm{NaOMe}$ to $\mathrm{Na}_{2} \mathrm{CO}_{3}$ and $\mathrm{HCO}_{2} \mathrm{Na}$ is supported in each of the analytical techniques enlisted: ${ }^{1} \mathrm{H}$ NMR, ${ }^{13} \mathrm{C} \mathrm{NMR},{ }^{23} \mathrm{Na}$ ssNMR, Raman spectroscopy, and Karl Fischer.

Table $1 .{ }^{23} \mathrm{Na}$ MAS NMR spectral fitting results giving insights into the degraded $\mathrm{NaOMe}$ (Black spectrum in Figure 4). Fitting is completed using DMFit.

\begin{tabular}{ccc}
\hline Component no. & $\%$ & Proposed degradant \\
\hline 1 & 12.52 & $\mathrm{Na}_{2} \mathrm{CO}_{3}$ or $\mathrm{HCO}_{2} \mathrm{Na}$ \\
3 & 20.37 & $\mathrm{Na}_{2} \mathrm{CO}_{3}$ \\
4 & 48.45 & $\mathrm{HCO}_{2} \mathrm{Na}$ \\
& 18.66 & $\mathrm{Na}_{2} \mathrm{CO}_{3}$
\end{tabular}

Having established unambiguously that sodium alkoxide salts are capable of decomposing into a variety of other sodium salts in the solid state, we next sought to establish a general picture of the kinetics and mechanism of these processes. To this end, the decomposition of $\mathrm{NaOMe}$ under air was tracked as a model system (Figure 6). Upon holding a sample of authentic $\mathrm{NaOMe}$ in air for five days, a small peak for sodium formate began to appear by ${ }^{1} \mathrm{H}$ NMR in addition to a new major peak present in both the ${ }^{1} \mathrm{H}$ and ${ }^{13} \mathrm{C}$ NMR, which was identified as sodium methyl carbonate (SMC). Sodium methyl carbonate is formed from the reaction of sodium methoxide with carbon dioxide ${ }^{[19]}$ Reanalysis of the sample in $\mathrm{D}_{2} \mathrm{O}$ after 18 hours resulted in nearly complete consumption of SMC by ${ }^{1} \mathrm{H}$ NMR. While no new impurities are observed by ${ }^{1} \mathrm{H}$ NMR (blue spectrum), ${ }^{13} \mathrm{C}$ NMR analysis indicates that this sample is cleanly converted from $\mathrm{SMC}$ to $\mathrm{Na}_{2} \mathrm{CO}_{3}$ (see $\mathrm{SI}$ ). Interestingly, despite a clear difference in quality and state of decomposition, the fresh lot of $\mathrm{NaOMe}$ (red spectrum) and the decomposed sample (blue spectrum) are nearly identical by ${ }^{1} \mathrm{H}$ NMR analysis and are also indistinguishable visually (both are white, free-flowing solids). 


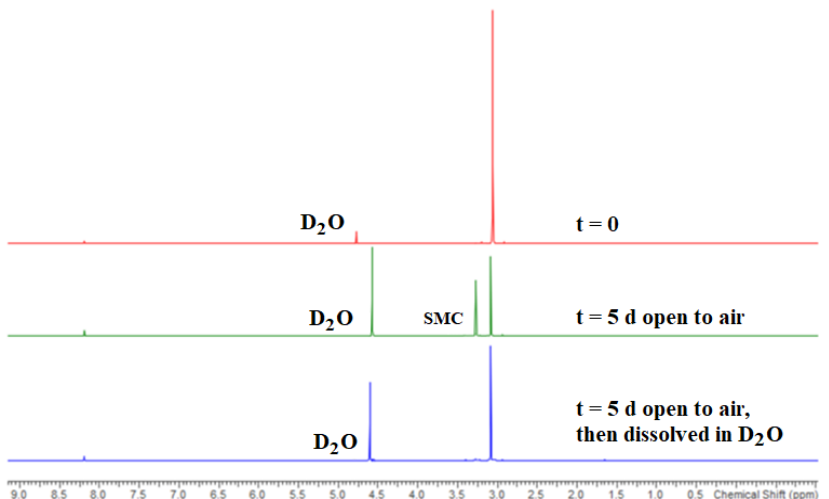

Figure 6. ${ }^{1} \mathrm{H}$ NMR degradation study. Initial spectra of $t=0$ (red). Solid sample held for $5 \mathrm{~d}$ at room temperature open to air (green). Solid sample held under air at RT for $5 \mathrm{~d}$, then dissolved in $\mathrm{D}_{2} \mathrm{O}$ for $18 \mathrm{~h}$ at RT (blue).

Storage of $\mathrm{NaOMe}$ in a $\mathrm{CO}_{2}$-rich environment did lead to the appearance of SMC, but extended hold times of this sample in $\mathrm{D}_{2} \mathrm{O}$ result in decomposition to sodium bicarbonate rather than sodium carbonate, as indicated by ${ }^{13} \mathrm{C}$ NMR. ${ }^{[20]}$ Once again, this decomposed sample is indistinguishable from a pure lot of $\mathrm{NaOMe}$ visually and by ${ }^{1} \mathrm{H}$ NMR. These results suggest that the storage conditions of the sodium methoxide can greatly impact the amount and type of degradation products observed. It is postulated that a $\mathrm{CO}_{2}$-rich environment would result in rapid and complete conversion of $\mathrm{Na}$ OMe into SMC, whereupon introduction of $\mathrm{D}_{2} \mathrm{O}$ would result in $\mathrm{NaDCO}_{3}$ production. Alternatively, under air, only partial decomposition of $\mathrm{NaOMe}$ would take place, followed by either (1) methoxide-promoted demethylation of SMC, or (2) hydrolysis and methoxide-promoted deprotonation of $\mathrm{NaDCO}_{3}$ (Figure 7). Either way, the rate of decomposition of sodium methoxide with atmospheric levels of $\mathrm{CO}_{2}$ (currently around $412 \mathrm{ppm}$ ) is remarkable.

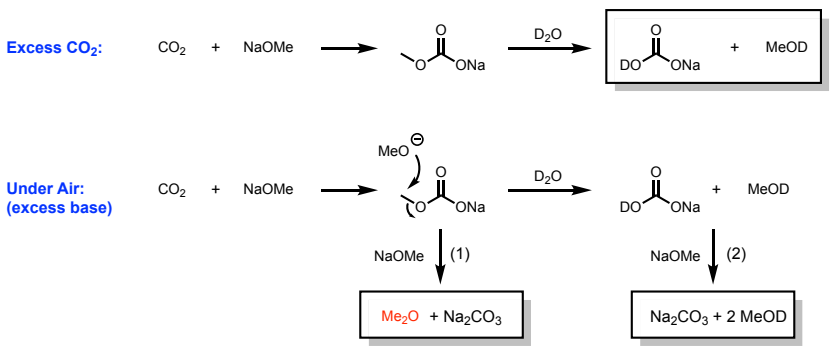

Figure 7. Postulated decomposition pathways for $\mathrm{NaOMe}$ under $\mathrm{CO}_{2}$ or air atmosphere.

Although it is infeasible to quantitatively track each inorganic degradant arising from $\mathrm{NaOMe}$ over time, we nevertheless wanted to have an idea of how long $\mathrm{NaOMe}$ is stable under various conditions. When monitoring $\mathrm{NaOMe}$ left open to the air by Raman spectroscopy over time, changes in the spectra are observed in a matter of hours, indicating that decomposition begins almost immediately (Figure 8). Further experiments show that both the rate and pathway of degradation are influenced by the atmospheric conditions and surface area exposed. Raman sampling of material near the airsolid interface show decomposition occurring; in contrast, sampling of material well below the interface shows non-degraded material until such time that air has penetrated deeper into the sample. After leaving the sample exposed to air, mixing it, and reanalyzing it, the data showed that degradation was more progressed on the surface. However, we found that under a dry nitrogen environment, there was no detection of degradation over several days. Therefore, we suggest storing these sodium alkoxides salts under an inert atmosphere.

Having a better understanding of the degradation of $\mathrm{NaOMe}$, we performed a similar series of experiments on various lots of sodium ethoxide, which is similarly unstable and decomposes into sodium acetate $(\mathrm{NaOAc})$ and $\mathrm{HCO}_{2} \mathrm{Na} \cdot{ }^{[21]}$ Preliminary experiments with a representative tertiary sodium alkoxide salt, $\mathrm{NaO} t$ - $\mathrm{Bu}$, revealed solid-state decomposition, as tracked by Raman spectroscopy. ${ }^{[21]}$ Though full characterization of the major degradant(s) of $\mathrm{NaOt}$-Bu is outside of the scope of the present study, the plausible pathway would again involve initial reaction with $\mathrm{CO}_{2}$ to yield sodium tertbutyl carbonate. We briefly evaluated alkoxide bases containing other metal cations, namely KOMe and LiOMe, which did not show decomposition over two days when exposed to air. This unique decomposition appears to be particularly facile with sodium alkoxides under normal handling conditions for reasons that remain unclear at this time.

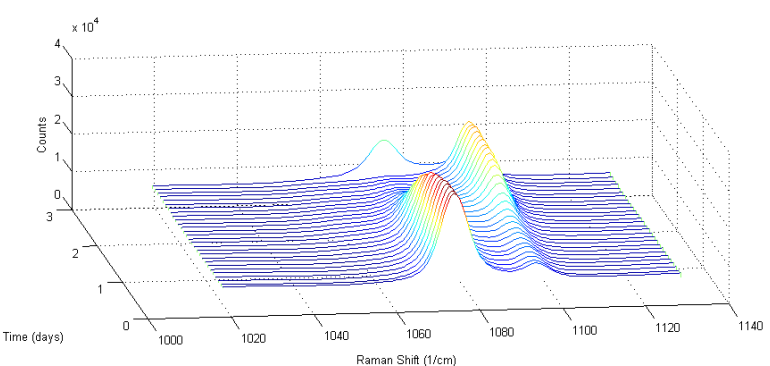

Figure 8. Degradation of $\mathrm{NaOMe}$ over time by Raman Spectroscopy. Continual scanning of the solid-air interface of the vial over $3 \mathrm{~d}$. Final scan was well below the solid-air interface of the vial, demonstrating no decomposition occurred below the surface.

In summary, we have described the decomposition of solid samples of $\mathrm{NaOMe}$ and $\mathrm{NaOEt}$ to various inorganic salts under air, a phenomenon that surprisingly does not appear to be accompanied by any change to physical appearance. By enlisting a batter of analytical techniques, we were able to identify principal degradants and obtain a preliminary understanding of the kinetics of the process at the solid-air interface. The pervasive nature of decomposition-even within "new" commercial lots-has widespread implications for methodology that employs sodium alkoxide bases, particularly given the unreliability of visual quality checks. As we have experienced firsthand in both academic and industrial research settings, reaction reproducibility can be heavily impacted by the batch-to-batch quality differences of these bases as well as the temporal instability of a given sample. We anticipate that the analytical methods described herein will serve as important quality tests that can be routinely used by organic chemists working with these chemicals. Moreover, by systematically studying this decomposition process and its impact on cross-coupling reactivity, we hope to draw attention to the extra precautions that should be kept in mind when employing solid $\mathrm{NaOMe}$ and $\mathrm{NaOEt}$. 


\section{ASSOCIATED CONTENT}

\section{Supporting Information}

Detailed experimental procedures, spectroscopic data, and compound characterization. This material is available free of charge via the Internet at http://pubs.acs.org.

\section{AUTHOR INFORMATION}

\section{Corresponding Author}

Steven.Wisniewski@bms.com, John.Coombs@bms.com, keary@scripps.edu

\section{ACKNOWLEDGMENT}

This work was financially supported by the National Science Foundation (CHE-1800280) and Bristol Myers Squibb. We further acknowledge the National Science Foundation for Graduate Research Fellowships (DGE-1346837, J.D. and DGE-1842471, O.A.) and the Kwanjeong Educational Foundation for a Graduate Fellowship (T.K.).

\section{REFERENCES}

(1) Bradley, D. C. Metal Alkoxides. In Progress in Inorganic Chemistry, Cotton, F. A., Ed.; Wiley \& Sons: New York, 1960; pp 303-361.

(2) (a) El-Kattan, Y.; McAtee, J.; Bessieres, B. Sodium Methoxide. In eEROS Encyclopedia of Reagents for Organic Synthesis [Online]; Wiley \& Sons, Posted Sep 15, 2006. http://onlinelibrary.wiley.com/doi/10.1002/047084289X.rs089m.pub2/ (accessed Aug 12, 2020). (b) Whitaker, K. S.; Whitaker. D. T. Sodium Ethoxide. In e-EROS Encyclopedia of Reagents for Organic Synthesis [Online]; Wiley \& Sons, Posted Apr 15, 2001. https://onlinelibrary.wiley.com/doi/full/10.1002/047084289X.rs070 (accessed Aug 12, 2020). (c) Chandra, K.; Nithya, R.; Sankaran, K.; Gopalan, A.; Ganesan. V. Synthesis and Characterization of Sodium Alkoxides. Bull. Mater. Sci. 2006, 29, 173-179. (d) Beske, M.; Tapmeyer, L.; Schmidt. M. U. Crystal Structure of Sodium Ethoxide $\left(\mathrm{C}_{2} \mathrm{H}_{5} \mathrm{ONa}\right)$, Unravelled after 180 Years. Chem. Commun. 2020, 56, 3520-3523.

(3) For representative reviews, see: (a) Miyaura, N.; Suzuki. A. Palladium-Catalyzed Cross-Coupling Reactions of Organoboron Compounds. Chem. Rev. 1995, 95, 2457-2483. (b) Chemler, S. R.; Trauner, D.; Danishefsky. S. J. The B-Alkyl Suzuki-Miyaura Cross-Coupling Reaction: Development, Mechanistic Study, and Applications in Natural Product Synthesis. Angew. Chem., Int. Ed. 2001, 40, 4544-4568. (c) Jana, R.; Pathak, T. P.; Sigman. M. S. Advances in Transition Metal (Pd,Ni,Fe)-Catalyzed Cross-Coupling Reactions Using Alkyl-Organometallics as Reaction Partners. Chem. Rev. 2011, 111, 1417-1492. For representative recent methods using primary sodium alkoxide salts, see: (d) Semba, K.; Nakao. Y. Arylboration of Alkenes by Cooperative Palladium/Copper Catalysis. J. Am. Chem. Soc. 2014, 136, 7567-7570. (e) Basch, C. H.; Cobb, K. M.; Watson. M. P. NickelCatalyzed Borylation of Benzylic Ammonium Salts: Stereospecific Synthesis of Enantioenriched Benzylic Boronates. Org. Lett. 2016, 18, 136-139. (f) Kim, J.; Cho. S. H. Access to Enantioenriched Benzylic 1,1-Silylboronate Esters by Palladium-Catalyzed Enantiotopic-Group Selective Suzuki-Miyaura Coupling of (Diborylmethyl)silanes with Aryl Iodides. ACS Catal. 2019, 9, 230-235.

(4) In our experience even 'new' commercial bottles can show evidence of significant degradation depending on the lot and supplier, likely due to upstream handling under non-inert conditions, followed by prolonged storage.

(5) (a) Tiwari, A.; Raj. B. Reactions and Mechanisms. In Thermal Analysis of Advanced Materials, Wiley \& Sons: New York, 2015; pp 333-390. (b) Chandra, K.; Kamruddin, M.; Ajikumar, P. K.; Gopalan, A.; Ganesan. V. Kinetics of Thermal Decomposition of Sodium Methoxide and Ethoxide. $J$. Nucl. Mater. 2006, 358, 111-128. (c) Bastos, F. A.; Khan, S.; Simoes, E. H.; Teixeira, C. A.; Tubino. M. Thermometric Quantitative Selective Analysis of Sodium Methoxide in Methanol Industrial Solutions. J. Braz. Chem. Soc. 2013, 24, 1380-1384.

(6) Once received in our respective labs, the lots of $\mathrm{NaOMe}$ and $\mathrm{NaOEt}$ (later found to be significantly degraded) had been stored in a dry desiccator. However, no additional protection from laboratory air was taken during storage.

(7) It is important to note that this particular sample of degraded sodium methoxide was originally synthesized by a commercial vendor approximately 4 years prior to these studies. It has been stored in a dry desiccator upon being receiving, but the previous history regarding how many times it was exposed to air is unknown.

(8) See Supporting Information for ${ }^{1} \mathrm{H}$ NMR spectrum.

(9) Derosa, J.; Kleinmans, R.; Tran, V. T.; Karunananda, M. K.; Wisniewski, S. R.; Eastgate, M. D.; Engle, K. M. Nickel-Catalyzed 1,2-Diarylation of Simple Alkenyl Amides. J. Am. Chem. Soc. 2018, 140, 17878-17883.

(10) Zhou, Q.; Srinivas, H. D.; Dasgupta, S.; Watson. M. P. Nickel-Catalyzed Cross-Couplings of Benzylic Pivalates with Arylboroxines: Stereospecific Formation of Diarylalkanes and Triarylmethanes. J. Am. Chem. Soc. 2013, 135, 3307-3310.

(11) We did not utilize IR spectroscopy since the sample would need to be in contact with the probe or benchtop unit ATR diamond window. We did use IR spectroscopy for sodium ethoxide due to the fluorescence of these samples but did not perform a time study. While this would be possible, the amount of sample studied would be small and the relative amount of sample exposed to the air would be very high, so decomposition is likely to proceed very quickly and would not be representative of storage in a bottle. The Raman non-contact sampling allowed us to more closely replicate a bottle storage environment.

(12) For recent examples utilizing ${ }^{23} \mathrm{Na}$ ssNMR, see: (a) Vallee, C.; Saubanere, M.; Sanz-Camacho, P.; Biecher, Y.; Fraisse, B.; Suard, E.; Rousse, G.; Carlier, D.; Berthelot, R. Alkali-Glass Behavior in Honeycomb-Type Layered $\mathrm{Li}_{3-\mathrm{x}} \mathrm{Na}_{x} \mathrm{Ni}_{2} \mathrm{SbO}_{6}$ Solid Solution. Inorg. Chem. 2019, 58, 11546-11552. (b) Anjali, K.; Ajithkumar, T. G.; Joy, P. A. Raman and ${ }^{23} \mathrm{Na}$ Solid-State NMR Studies on the Lead-Free Ferroelectrics $\mathrm{Bi}_{0.5}\left(\mathrm{Na}_{1-\mathrm{x}} \mathrm{K}_{\mathrm{x}}\right)_{0.5} \mathrm{TiO}_{3}$ in the Morphotropic Phase Boundary Region. Mat. Res. Bull. 2019, 118, 110506 110513. (c) Gouget, G.; Duttine, M.; Durand, E.; Villesuzanne, A.; Rodriguez, V.; Adamietz, F.; Le Mercier, T.; Braida, M.-D.; Demourgues, A. Isolating the Two Room-Temperature Polymorphs of $\mathrm{NaNbO}_{3}$ : Structural Features, Optical Band Gap, and Reactivity. ACS Appl. Electron. Mater. 2019, 1, 513-522. (d) Ohashi, R.; Michal, C. A.; Hamad, W. Y.; Nguyen, T.D.; Mizuno, M.; MacLachlan, M.J. Solid-State ${ }^{23}$ Na NMR Spectroscopy Studies of Ordered and Disordered Cellulose Nanocrystal Films. Solid State Nucl. 2019, 97, 31-39. (e) Tian, M.; Buchard, A.; Wells, S. A.; Fang, Y.; Torrente-Murciano, L.; Nearchou, A.; Dong, Z.; White, T. J.; Sartbaeva, A.; Ting, V. P. Mechanism of $\mathrm{CO}_{2}$ Capture in Nanostructured Sodium Amide Encapsulated in Porous Silica. Surf. Coat. Technol. 2018, 350, 227-233. (f) Haffner, A.; Hatz, A.-K.; Moudrakovski, I.; Lotsch, B. V.; Johrendt, D. Fast Sodium-Ion Conductivity in Supertetrahedral Phosphidosilicates. Angew. Chem. Int. Ed. 2018, 57, 6155-6160. (g) Hummel, T.; Mos-Hummel, A.; Merkulova, A.; Strobele, M.; Krishnamurthy, A.; Kroeker, S.; Meyer, H.-J. Lithium and Sodium Ion Distributions in $\mathrm{A}_{2-\mathrm{x}}\left[\mathrm{W}_{6} \mathrm{I}_{14}\right]$ Structures. Inorg. Chem. 2018, 57, 2570-2576.

(13) (a) Jacobs, H.; Metzner, U. Ungewöhnliche H-Brückenbindungen in Natriumhydroxidmonohydrat: Röntgen- und Neutronenbeugung an $\mathrm{NaOH} \cdot \mathrm{H}_{2} \mathrm{O}$ bzw. NaOD$\cdot \mathrm{D}_{2} \mathrm{O}$. Anorg. Allg. Chem. 1991, 597, 97-106. (b) Hemily, P. W. Structures Cristallines des Hydrates de la Soude. I. Structure Cristalline de $\mathrm{NaOH} .4 \mathrm{H}_{2} \mathrm{O}$. Acta. Cryst. 1957, 10, 37-44. (c) Hemily, P. W. Structures Cristallines des Hydrates de la Soude. II. Structures Pseudo-Homométriques de $\mathrm{NaOH} .4 \mathrm{H}_{2} \mathrm{O}$. Acta. Cryst. 1957, 10, 45-47. (d) Wunderlich, J. A. Structures Cristallines des Hydrates de la Soude. III. La Structure Cristalline de $\mathrm{NaOH}$. $\mathrm{H}_{2} \mathrm{O}$. Acta. Cryst. 1957, 10, 462-463. (e) Hemily, P. W.; Wunderlich, J. A. Structures Cristallines des Hydrates de la Soude. IV. Études Cristallographiques de Neuf Phases du Système $\mathrm{NaOH} / \mathrm{H}_{2} \mathrm{O}$. Acta. Cryst. 1957, 10, 454-456.

(14) Weiss, E. Z. Die Kristallstruktur des Natriummethylats. Anorg. Allg. Chem. 1964, 332, 197-203.

(15) Zachariasen, W. H. The Crystal Structure of Sodium Formate, $\mathrm{NaHCO}_{2}$. J. Am. Chem. Soc. 1940, 62, 1011-1013. 
(16) (a) Haper, J. P. Crystal Structure of Sodium Carbonate Monohydrate, $\mathrm{Na}_{2} \mathrm{CO}_{3} . \mathrm{H}_{2} \mathrm{O}$. Z. Krist-Cryst Mater. 1936, 95, 266-273. (b) Dickens, B.; Mauer, F. A.; Brown. W. E. A refinement of the crystal structure of $\mathrm{Na}_{2} \mathrm{CO}_{3} \cdot \mathrm{H}_{2}$ O. J. Res. Nat. Bur. Stand., Sect. A. 1970, 74A, 319-324.

(17) Massiot, D.; Fayon, F.; Capron, M.; King, I.; Le Calvé, S.; Alonso, B.; Durand, J.-O.; Bujoli, B.; Gan, Z.; Hoatson, G. Modelling One-and TwoDimensional Solid-State NMR Spectra. Magn. Reson. Chem. 2002, 40, 70 76.

(18) $\mathrm{Na}_{2} \mathrm{CO}_{3}$ seems to have two or more components, whereas $\mathrm{HCO}$ $\mathrm{ONa}$ seems to have one or two components. The multiple components in $\mathrm{Na}_{2} \mathrm{CO}_{3}$ are either from multiple polymorphs or from $Z^{\prime}=2$ of one polymorph, and those of HCOONa are from multiple polymorphs.
(19) (a) Brillon, D.; Suavé. G. A New Preparation of Difunctionalized Enamines from Thioamides Using Silver (I) Carbonate. J. Org. Chem. 1990, 55, 2246-2249. (b) Hurst, T. E.; Deichert, J. A.; Kapeniak, L.; Lee, R.; Harris, J.; Jessop, P. G.; Snieckus. V. Sodium Methyl Carbonate as an Effective C1 Synthon. Synthesis of Carboxylic Acids, Benzophenones, and Unsymmetrical Ketones. Org. Lett. 2019, 21, 3882-3885.

(20) See Supporting Information for ${ }^{1} \mathrm{H}$ NMR Spectrum.

(21) See Supporting Information for studies on the degradation of $\mathrm{NaOEt}$ and $\mathrm{NaO} t-\mathrm{Bu}$ 


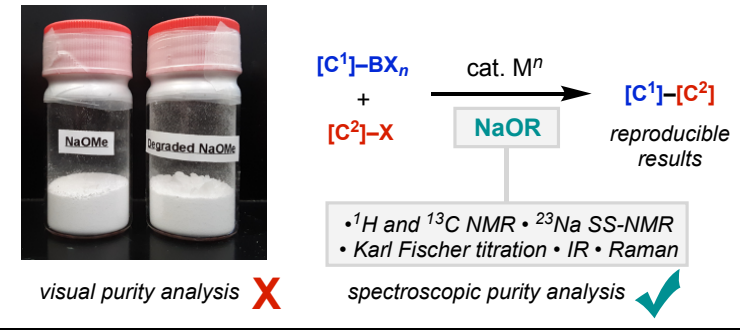

